\title{
EDITORIAL
}

\section{UN CAMBIO DE PARADIGMA EN LA REGULACIÓN LABORAL DE LAS CONTRATAS}

Miguel Rodríguez-Piñero Royo

Director

A estas alturas de la legislatura es claro que estamos en mitad de un proceso de reforma laboral, que ha producido ya cambios importantes en nuestra legislación, en temas nucleares además. Es un proceso atípico, que adopta una forma diferente a la que suele usarse en España. Aquí, en efecto, lo común son cambios más espectaculares, en normas de urgencia que modifican multitud de instituciones. Las denominamos por su año, y generalmente las hay de dos tipos: las mayores, en situaciones muy críticas, impuestas unilateralmente; y las menores, sin tantas urgencias y muchas veces para implementar acuerdos de los interlocutores sociales. Las de 1994 y 2021 son ejemplos del primer tipo; las de 1999 y 2005, de las segundas.

Lo de ahora no encaja en este modelo. Se está produciendo una sucesión de medidas puntuales, centradas en temas concretos que el Gobierno considera prioritarios. En alguna ocasión se ha contado con el apoyo de los agentes sociales; en otros, la mayoría, solo han sido apoyadas por los sindicatos.

La novedad más significativa, frente a experiencias anteriores, es que todas estas medidas apuntan en la dirección de mejorar los derechos de las personas que trabajan. Esto se hace de dos maneras: reconociendo algunos nuevos; y asegurando la eficacia de los ya reconocidos. La desconexión digital y el registro de jornadas serían un ejemplo del segundo tipo; los nuevos permisos, del primero.

Llevamos tanto tiempo inmersos en el debate sobre la derogación de la reforma laboral de 2012 que hemos estado poco atentos a las modificaciones ya producidas. La sensación que se tiene es la de espera; de "tensa espera" para algunos sectores, a los que algunas de las medidas que se anuncian no agradan. Parece que la reforma está por venir, que llegará en algún momento cuando se agote el diálogo social, con o sin

Copyright: (C) Editorial Universidad de Sevilla. Este es un artículo de acceso abierto distribuido bajo los términos de la licencia de uso y distribución Creative Commons Reconocimiento-NoComercialSinObraDerivada 4.0 (CC BY-NC-ND 4.0)

e-ISSN: 2660-4884

Trabajo, Persona, Derecho, Mercado 4 (2021) 11-23 https://dx.doi.org/10.12795/TPDM.2021.i4.01 
éxito. Cuando lo cierto es que esta está ya entre nosotros; que faltan por producirse algunas de sus fases, quizás las de mayor volumen; pero que una parte está ya culminada. Basta con analizar los documentos en los que el Gobierno se planteaba los cambios a realizar (Acuerdo de Gobierno de la Coalición gubernamental, Plan de Recuperación, Transformación y Resiliencia) para comprobarlo.

Esta reforma "en cascada”, si se le puede llamar así, está ocupándose de un número elevado de aspectos del Derecho del Trabajo. Algunos vienen impuestos por la necesidad de desandar las innovaciones de 2012; otros, por la atención a problemas graves de nuestro mercado de trabajo en la tercera década del siglo. Uno de los temas que más atención está recibiendo en este proceso es el relativo a la ordenación de la subcontratación.

Esto tiene su interés, porque no es una que suela estar presente en los grandes paquetes reformadores. En la del 2012, por ejemplo, no se trató extensamente, por más que sí hubiera algunas medidas que afectaran directamente a su dinámica, como ocurrió con la preferencia aplicativa de los convenios de empresa. Tuvo que ser una de las "reformas menores", la de 2005, la que se ocupara directamente de modificar su régimen jurídico.

Estudiar el proceso de renovación de esta figura está más que justificado, a mi juicio, por varios motivos. El primero de ellos es la ubicuidad de esta figura, que se ha convertido en la forma prácticamente ordinaria de organizar la producción en las empresas y la prestación de servicios públicos en las Administraciones.

El segundo, que se ha constatado cómo la externalización está teniendo un impacto muy negativo en la calidad del empleo, por la confluencia de una serie de factores (competencia salarial entre empresas contratistas, presión de precios en los clientes, admisión de la contratación temporal).

El tercero es que en los últimos años se ha comprobado también la transversalidad de las contratas, de tal modo que estas se ven afectadas no solo por las innovaciones en su propia regulación, sino también por las que se producen en otras instituciones laborales. En el caso español, por poner el ejemplo más cercano, su dinámica ha cambiado radicalmente tras la introducción de la preferencia aplicativa de los convenios de empresa en el año 2012, y por los cambios jurisprudenciales sobre el contrato de obra o servicio determinado y sobre el concepto de sucesión de empresas.

El cuarto, y seguramente más importante, es que lo que ahora se pretende es un cambio de gran alcance, que va a suponer una completa transformación de nuestro modelo de ordenación de los aspectos laborales de la subcontratación. No se trata de cambios puntuales o de grado, sino que se van a tocar los elementos estructurales de esta regulación.

Vayamos por partes. Nuestro modelo regulatorio se caracteriza por algunas claves que llevan mucho tiempo en nuestras leyes, como resultado más de un proceso de afinamiento y mejora que de una construcción consciente en un único modelo. 
Iniciado en los años 50 del siglo pasado, con una marcada influencia de la legislación italiana en sus primeras fases, está marcado por una serie de elementos prácticamente estructurales que podemos identificar de la manera que sigue:

- Libertad de subcontratar: las empresas pueden decidir libremente, con muy escasas limitaciones derivadas de normativas especializadas.

- Libertad para prestar servicios como contratista, salvo las exigencias que puedan derivarse en algunos servicios específicos, como los de seguridad privada.

- Utilización de sistemas de garantía para tutelar los derechos de los trabajadores de las empresas contratistas, que operan principalmente en dos ámbitos: responsabilidad sobre obligaciones laborales; y derechos de información a los representantes de los trabajadores.

- La contratista es la única entidad empleadora del personal al servicio de la contrata. Esto tiene como consecuencia que las condiciones de trabajo de estas personas vengan determinadas por las que rigen en esta empresa, con independencia de las que se apliquen en la empresa principal. La contratista sería la responsable directa de todas las obligaciones laborales, aunque se involucre a la principal mediante técnicas de responsabilidad. Solo en aspectos relativos a la salud y seguridad esta última puede aparecer como responsable directa, en lo relacionado con las instalaciones en las que se prestan los servicios.

- La contrata es contemplada como obra o servicio determinado a efectos de la contratación del personal que va a desempeñar el servicio.

- Su finalización es causa de extinción del contrato de trabajo por causas objetivas, aunque esta posibilidad se fue limitando con el tiempo al imponer los tribunales la necesidad de acreditar la falta de ocupación alternativa; y al extenderse la aplicación del artículo 44 ET a las sucesiones de contrata.

- El cambio de contratista puede suponer, según las circunstancias del caso, una sucesión de empresas con efecto subrogatorio para el personal adscrito a la contrata.

Con esta regulación las contratas se han venido desarrollando en nuestro país sin grandes problemas. El mayor ha sido históricamente su utilización fraudulenta, como una manera de enmascarar cesiones de mano de obra. Frente a esto, el legislador reaccionó mejorando los instrumentos para identificar estas últimas, con una nueva redacción del artículo 43 ET; y mejorando la vigilancia por parte de los representantes de los trabajadores. Los artículos 42 y 43 ET, soportados por una contundente construcción jurisprudencial, han servido mal que bien para establecer los límites de la externalización lícita en nuestro Derecho. 
Con el tiempo han surgido otros problemas vinculados al trabajo en contratas, frente a los que el ordenamiento ha demostrado estar mucho más limitado.

Una novedad legislativa en su momento, que tuvo un gran impacto en la realidad de las contratas, fue la prioridad aplicativa del convenio de empresa, que, en manos de empresarios ventajistas, se convirtió en un instrumento de competitividad, especialmente en la contratación pública, generando ofertas de bajo coste y pésimas condiciones laborales. La aparición del modelo de empresas multiservicios también tuvo su impacto, como ocurrió con las experiencias de privatización y "desprivatización" en los servicios públicos.

El resultado de la interacción de todos estos factores es que trabajar en contratas se ha convertido en un factor de precarización contractual y salarial. Este fenómeno, muy evidente en los últimos años, no podía pasar desapercibido en un momento como el actual, en el que las preocupaciones por la calidad del empleo se han vuelto prioritarias. Superados los efectos más nocivos sobre el empleo de la crisis financiera mundial, las consecuencias de esta y de las reformas laborales de la época sobre los aspectos cualitativos del trabajo han llevado a colocar a estos como el principal objetivo de las políticas laborales. Ya en legislaturas anteriores se generaron debates al respecto, con propuestas recurrentes. El cambio de Gobierno las convirtió en verdaderas iniciativas de medidas legislativas, que a la fecha todavía no se han materializado. Lo que es claro, en todo caso, es que el trabajo en contratas es uno de los núcleos temáticos del proceso de reformas de 2020-2021; y que la regulación que de esta figura encontraremos en el "Estatuto de los Trabajadores del siglo XXI", que está en trámite de elaboración, será muy diferente a la que tenemos en el Estatuto vigente.

La necesidad de mejorar esta regulación es tan evidente que algunos cambios ya se han producido. Así ha ocurrido con la legislación de contratación pública. De esta manera, la Ley 9/2017, de 8 de noviembre, de Contratos del Sector Público, por la que se transponen al ordenamiento jurídico español las Directivas del Parlamento Europeo y del Consejo 2014/23/UE y 2014/24/UE, de 26 de febrero de 2014, ha impuesto varias medidas de mejora para las personas empleadas por contratistas públicos, a la vez que se pretende impedir la competencia desleal entre estos sobre la erosión de las condiciones salariales. Una de estas medidas se contiene en su artículo 122, en el que se dispone lo siguiente:

"En los pliegos de cláusulas administrativas particulares se incluirán los criterios de solvencia y adjudicación del contrato; las consideraciones sociales, laborales y ambientales que como criterios de solvencia, de adjudicación o como condiciones especiales de ejecución se establezcan... la obligación del adjudicatario de cumplir las condiciones salariales de los trabajadores al convenio colectivo sectorial de aplicación y las demás menciones requeridas por esta ley y sus normas de desarrollo".

Mientras que en el artículo 149 se afirma: 
"En todo caso, los órganos de contratación rechazarán las ofertas si comprueban que son anormalmente bajas porque vulneran la normativa sobre subcontratación o no cumplen las obligaciones aplicables en materia medioambiental, social o laboral, nacional o internacional, incluyendo el incumplimiento de los convenios colectivos sectoriales vigentes".

Con estas previsiones no se altera, es cierto, ninguno de los elementos estructurales del modelo tradicional, ya que se parte de que se aplique a los empleados de los contratistas públicos el convenio de su sector, asumiendo la condición de empleadora de estas. Pero sí se intenta impedir la práctica antes señalada de obtención de ventajas para competir en los concursos públicos mediante convenios de empresa de baja calidad que se aplicaban de manera preferente gracias a la reforma de 2012.

En la misma dirección apunta el artículo 202, según el cual

"las consideraciones de tipo social o relativas al empleo, podrán introducirse, entre otras, con alguna de las siguientes finalidades: garantizar la seguridad y la protección de la salud en el lugar de trabajo y el cumplimiento de los convenios colectivos sectoriales y territoriales aplicables".

Otra novedad de gran alcance en el Derecho de las contratas lo ha sido el cambio progresivo en la jurisprudencia de la Sala de lo Social del Tribunal Supremo respecto de la posibilidad de utilizar contratos temporales por parte de empresas contratistas. En esto, como en tantas otras áreas de nuestro Derecho del Trabajo, la influencia del Derecho Social Unioneuropeo y de la interpretación del Tribunal de Justicia han sido determinantes para una evolución de enorme importancia. Como es sabido, en una primera fase, el Tribunal Supremo determinó la inadecuación del contrato de obra cuando se trataba de subcontrataciones de muy larga duración; para pasar de manera muy rápida, en una segunda fase, a considerar inadecuado este contrato de obra cuando la actividad habitual de una empresa fuera la externalización de actividades para sus clientes.

Las consecuencias fueron de gran alcance. A partir de ese momento, no podía considerarse que una contrata fuera una obra o servicio determinado para la empresa contratista, sino su actividad ordinaria, que debía prestarse mediante contratos indefinidos. En consecuencia, la terminación de los contratos a la finalización de contrata debía articularse mediante despido. Una de las claves del modelo clásico de regulación laboral de las contratas había caído, así.

Estas son innovaciones ya producidas. Hay otras en espera de implementarse, que están diseñadas en textos de distinta naturaleza, que expresan (o demandan) compromisos gubernamentales. Ya desde la anterior legislatura se plantearon propuestas sobre los aspectos laborales de las contratas, con escasos visos de ver la luz, pero con la clara intención de poner de manifiesto la voluntad de sectores políticos de cambiar la situación, y la existencia de modelos alternativos al vigente. 
Estas propuestas se plantean como objetivos: dotar de seguridad jurídica a la propia subcontratación, afrontando los aspectos de calificación dudosa (cesión vs contrata, propia actividad $v$ s actividad auxiliar); evitar la competencia desleal entre las empresas de un mismo sector, basada en la degradación de las condiciones laborales y en la rebaja de la calidad en la prestación de servicios; asegurar que los trabajadores que presten servicios en un mismo sector tengan garantizado el mismo salario y las mismas condiciones de trabajo; y, en general, mejorar la calidad del empleo de las personas que trabajan para empresas contratistas. Para ello se han diseñado unos instrumentos originales (en relación con la situación anterior) y potencialmente incisivos (cambiando radicalmente esta). Vamos a encontrar así: propuestas sobre la imposición de una igualdad de trato con los trabajadores de la principal; nuevas obligaciones de información; nuevas definiciones de los conceptos básicos; limitaciones al uso de los contratos de obra o servicio; o, incluso, la restricción de la capacidad de externalización de las empresas.

A continuación, estudiaré brevemente algunos de los documentos más relevantes, a mi juicio, de entre los puestos en circulación durante los últimos años.

El primer texto relevante a manejar es el Pacto de Gobierno PSOE-UP denominado "Un nuevo acuerdo para España”, de diciembre de 2019, que incluye un completo paquete de compromisos en materia laboral. Bajo el título "Derogaremos la reforma laboral. Recuperaremos los derechos laborales arrebatados por la reforma laboral de 2012", los dos Partidos de la Coalición de Gobierno afirmaron lo siguiente: "impulsaremos en el marco del diálogo social la protección de las personas trabajadoras y recuperaremos el papel de los convenios colectivos". Para ello se preveían una serie de medidas que debían adoptarse con carácter urgente (derogación del despido por absentismo causado por bajas por enfermedad; derogación de las limitaciones al ámbito temporal del convenio colectivo; eliminación de la prioridad aplicativa de los convenios de empresa sobre los convenios sectoriales). Junto a estas medidas se incluía una específica sobre subcontratación: "modificaremos el art. 42.1 del Estatuto de los Trabajadores sobre contratación y subcontratación laboral a efectos de limitar la subcontratación a servicios especializados ajenos a la actividad principal de la empresa”. Aparece aquí un elemento que podemos considerar bastante radical, porque ataca uno de los pilares del modelo tradicional (y todavía vigente en gran medida): la libertad para subcontratar.

En marzo de 2021 se aprobó en la Comisión de Trabajo, Inclusión, Seguridad Social y Migraciones del Congreso de los Diputados una Proposición no de Ley presentada por el Grupo Parlamentario Socialista, relativa a igualar las condiciones salariales de los trabajadores subcontratados (número 161/001782). El texto de la proposición es el siguiente:

"El Congreso de los Diputados insta al Gobierno a adoptar las medidas normativas que permitan asegurar que las personas trabajadoras que sean contratadas para realizar 
servicios comprendidos dentro de la propia actividad del empresario principal tengan las mismas condiciones que tendrían de ser contratados directamente por éste, tanto si dichas condiciones traen causa del convenio colectivo de la empresa principal como si son acordadas por dicha empresa en el momento de la contratación.

La propuesta normativa en cuestión sería adoptada por parte del Gobierno antes del 30 de junio de $2021 "$.

Como se ve, en esta se insta al Gobierno a modificar el Estatuto de los Trabajadores para garantizar a las personas empleadas por empresas contratistas las mismas condiciones que tendrían de ser contratados directamente por la empresa principal, sea cual fuera el origen, convencional o contractual, de estas. Esto es, se extiende a las contratas el principio de equiparación salarial previsto ya para los trabajadores en misión. Esta equiparación solo aplicaría en contratas para prestar servicios comprendidos dentro de la propia actividad del empresario principal.

A esta proposición se le presentaron dos enmiendas por el Grupo Republicano, que incluyeron nuevos contenidos a tratar en una posible reforma de la legislación vigente en la materia:

"2. Adoptar las medidas normativas que permitan asegurar que la contratación por el empresario principal con una empresa contratista de la realización de obras o servicios correspondientes a su propia actividad, así como los posteriores cambios de contrata o subcontrata y el retorno a la propia empresa principal, no extinguirá por sí misma la relación laboral de los trabajadores, quedando el nuevo empresario subrogado en los derechos y obligaciones laborales y de Seguridad Social del anterior, en los términos y con las consecuencias previstas en los apartados anteriores. De tal forma, la contratación y subcontratación de obras y servicios por parte de la empresa, ya sea de naturaleza civil, mercantil o administrativa, en ningún caso constituirá causa que justifique por sí misma la celebración de esta modalidad contractual. Las medidas normativas en cuestión, serán adoptadas por parte del gobierno y vigentes en el ordenamiento jurídico laboral antes del día 30 de junio de 2021.

3. Adoptar las medidas normativas que permitan asegurar que no se producirá la contratación por el empresario principal con una empresa contratista de la realización de obras o servicios correspondientes a su propia actividad salvo cuando las circunstancias del mercado, acumulación de tareas o exceso de pedidos así lo exigieran o por causa de fuerza mayor. Por convenio colectivo de ámbito, podrá acordarse y determinarse las circunstancias y condiciones en las cuales se producirán estas subcontrataciones. Las medidas normativas en cuestión, serán adoptadas por parte del gobierno y vigentes en el ordenamiento jurídico laboral antes del día 30 de junio de 2021”.

Los cambios propuestos son igualmente trascendentes: por un lado, se quiere impedir que la subcontratación y los cambios de contratista sean causa para extinguir los contratos de trabajo, imponiendo por mandato legal la subrogación que hoy prevén 
algunos convenios colectivos y exigen muchos concursos públicos. También se prevé, aunque parece haber un error en la redacción, que la subcontratación no pueda justificar la contratación temporal de los trabajadores. Por otro lado, se pretende limitar la capacidad de de externalización por parte de las empresas, estableciendo que solo se podrá subcontratar las que sean de su propia actividad en tres supuestos: cuando lo exijan las circunstancias del mercado, acumulación de tareas o exceso de pedidos; por causa de fuerza mayor; o cuando lo permita el convenio colectivo. La ley entraría en espacios reservados hasta ahora a la decisión empresarial, valorando la justificación de la medida desde parámetros que ella misma marcara. Curiosamente, se utilizan las causas que hoy justifican la contratación de duración determinada para legitimar la externalización, cuando la realidad es que esta última se justifica normalmente por causas de especialización técnica más que de volumen de actividad.

El Gobierno lo ha incluido en el paquete de medidas que ha enviado a Bruselas, el llamado "Plan de Recuperación, Transformación y Resiliencia". La Política palanca VIII "Nueva economía de los cuidados y políticas de empleo" incluye un componente 23, denominado "Nuevas políticas de empleo para un mercado dinámico, resiliente e inclusivo". Una de sus iniciativas (la identificada como R9) lleva por título "Modernización de la contratación y subcontratación de actividades empresariales"

Es interesante la descripción de la medida que se propone desarrollar:

"La contratación y subcontratación entre empresas (artículo 42 Estatuto Trabajadores) es una actividad muy extendida en todas las economías. Las empresas subcontratan de forma habitual parte de su actividad en aras de obtener una mayor agilidad y flexibilidad (en trabajos ocasionales, especializados, asociados a un proyecto determinado, etc.), y se valen del suministro de servicios complementarios para su actividad económica principal (comedores, servicios de vigilancia, etc.). Es necesario, sin embargo, abordar una reforma que impida que se utilice la externalización de servicios a través de la subcontratación como mecanismo de reducción de los estándares laborales de las personas que trabajan para las empresas subcontratistas. El incremento en el uso de la externalización productiva como mecanismo de reducción de costes afecta negativamente a la competencia cualitativa entre empresas e incide también en el incremento de la precariedad laboral. Por ello procede una modernización de su regulación que asegure un uso adecuado en los supuestos que mejoran la actividad productiva al tiempo que lo desincentive en aquellos en que es un mero instrumento de reducción de costes. Avanzar hacia la equiparación de condiciones entre trabajadoras y trabajadores subcontratados y reforzar la responsabilidad de las empresas contratistas o subcontratistas. Por ello, la adecuada regulación de la subcontratación constituye una sexta pieza clave del paquete de reformas que serán elevadas al Diálogo Social”.

El Plan aporta también sus argumentos para justificar esta iniciativa:

"b) Evidencia, análisis y datos que motiven la necesidad de la reforma: La subcontratación de servicios auxiliares, ajenos a la actividad principal, ha sido una práctica habitual 
en el modelo empresarial de nuestro país en especial de las grandes empresas. Sin embargo, en los últimos años, además de este modelo tradicional de subcontratación se utiliza cada vez más la externalización para subcontratar tareas que están dentro de la actividad propia de la empresa, del núcleo que define su negocio. Eso hace necesario una regulación precisa que garantice un nivel adecuado de protección a las personas trabajadoras de las subcontratas en relación a la actividad que realizan".

En cuanto a la forma de implementación de la reforma, se dice que esta

"implica cambios en la norma legal que regula los derechos de las personas que trabajan en las empresas subcontratadas, lo que implica la modificación del artículo 42 del Real Decreto Legislativo 2/2015, el Estatuto de los Trabajadores".

Será la Administración General del Estado la ejecutora de la reforma a través del Ministerio de Trabajo y Economía Social, en coordinación con el Ministerio de Asuntos Económicos y Transformación Digital. Se indica también que

"como paso inicial se abordará la negociación de su contenido con las organizaciones empresariales y sindicales más representativas en el marco del Diálogo Social, buscando el mayor nivel de consenso sobre estos cambios normativos que van a mejorar el funcionamiento del mercado de trabajo en España”.

Su calendario de implementación es el año 2021. El compromiso es muy claro: modificación del artículo $42 \mathrm{ET}$, previo diálogo con los interlocutores sociales; y el año 2021 para tenerla culminada.

Este año de 2021 es, pues, clave para la adopción de las medidas. Para poner en práctica este compromiso se ha puesto en marcha un proceso de diálogo social, en el que el Gobierno ha presentado sucesivos documentos de trabajo. En estos se incluye de manera recurrente una propuesta de modificación del artículo 42 ET, que se mantiene como base regulatoria del trabajo en contratas aunque con las novedades que se plantean.

Se mantiene la limitación que en su apartado 1 se ha hecho tradicionalmente, excluyendo a las empresas que contraten o subcontraten obras o servicios ajenas a su propia actividad. Señalo esto porque ha habido documentos gubernamentales en los que se eliminaba esta referencia, lo que suponía extender la obligación de comprobar que los contratistas están al corriente en el pago de las cuotas de la Seguridad Social a cualquier tipo de subcontratación.

Las principales novedades se producen en dos áreas. La primera en el alcance de la responsabilidad entre empresarios principal y contratista. Se mantiene en los mismos términos actuales la responsabilidad solidaria por las obligaciones salariales y las referidas a la Seguridad Social, así como las exclusiones tradicionales: cuando 
la actividad contratada se refiera exclusivamente a la construcción o reparación que pueda contratar una persona cabeza de familia respecto de su vivienda, y cuando no se subcontrate por razón de una actividad empresarial. Lo nuevo consiste en la introducción de un régimen diferente de responsabilidad, subsidiaria esta vez, cuando la actividad desarrollada por la empresa contratista no se considere propia de la principal. El alcance de esta nueva responsabilidad ha ido variando en las diferentes versiones del texto presentado a la negociación. Se ha hablado de que "la actividad desarrollada por la empresa contratista o subcontratista no forme parte del ciclo productivo de la empresa principal", entendiendo que "forman parte del ciclo productivo de la empresa principal aquellas operaciones y labores propias de la producción de bienes y servicios que constituyen el objeto de su actividad real o potencial, excluyendo solo aquellas actividades que estén desconectadas de dicho objeto". También se ha dicho que la responsabilidad subsidiaria regirá "en caso de que la empresa contratista o subcontratista desarrolle una actividad complementaria, que resulte estrictamente desconectada de la actividad productiva de la empresa principal o de su objeto, actual o potencial". La idea es clara, en todo caso: distinguir un doble círculo de responsabilidades, la solidaria para las que afecten al núcleo de la actividad de la empresa, y la subsidiaria para las que tengan un carácter auxiliar o especializado. El efecto es, en todo caso, ampliar el alcance de la compartición de las responsabilidades entre principal y contratista a un mayor número de supuestos y, por tanto, de personas trabajadoras.

La segunda novedad respecto de la regulación actual es que se prevé un nuevo apartado $6^{\circ}$ para el artículo $42 \mathrm{ET}$, en el que se dispone que "el convenio colectivo de aplicación para las empresas contratistas y subcontratistas será el del sector de la actividad ejecutada en la contrata o subcontrata, corresponda esta a la actividad propia de la principal o a una distinta, con independencia de la forma jurídica o el objeto social de la empresa contratista o subcontratista". Se impone, de esta manera, la aplicación del convenio sectorial para evitar las prácticas fraudulentas mediante la negociación de convenios de empresa. Esto va más allá de la mera supresión de la prioridad aplicativa del convenio de empresa, otra propuesta del Gobierno, para recoger una verdadera preferencia del convenio sectorial frente a los de otro nivel. Esto constituiría, por otro lado, una excepción respecto de la regla general sobre concurrencia de convenios recogida en el artículo $84 \mathrm{ET}$, puesto que el convenio sectorial prima con independencia de la fecha de firma de las distintas normas colectivas que concurren en un mismo ámbito. Se prevé, en todo caso, una excepción a esta prioridad aplicativa, ya que cuando la empresa contratista o subcontratista cuente con un convenio propio "podrá aplicar éste, siempre que esta norma convencional garantice, como mínimo, los mismos derechos que el convenio sectorial que corresponda a la actividad ejecutada en la subcontrata, en virtud de una apreciación conjunta de los conceptos comparables entre sî". No se llega tan lejos como se había propuesto 
cuando los Partidos de la Coalición estaban en la oposición, ya que entonces se llegaba a defender un principio de equiparación salarial entre los empleados de principal y contratista. Ahora se mantiene la aplicación del convenio según la empresa contratista, manteniéndose la idea de que esta es la única empleadora, a todos los efectos, del personal al servicio de la contrata.

Hay alguna modificación menor, dirigida a actualizar la redacción del precepto, como la sustitución de la expresión "cabeza de familia" por "persona cabeza de familia”. El resultado es un artículo 42 ET aún más extenso que el actual, uno de los "macropreceptos" que por acumulación de reformas y adiciones han ido surgiendo a lo largo del articulado del Estatuto. Es esta una técnica legislativa que a mi juicio habría que revisar, siendo más idóneo un desarrollo reglamentario del precepto estatutario que reduzca la extensión de este para que se concentre en los temas principales de la regulación. La práctica del legislador laboral va, sin embargo, en dirección contraria.

En fecha muy reciente (octubre de 2021), se ha hecho público un documento titulado "Manifiesto de abogados y abogadas laboralistas por la derogación de la reforma laboral", en el que, como su propio nombre indica, un colectivo de profesionales del Derecho del Trabajo se pronuncia sobre este debate. Su postura es clara: promover un cambio radical en nuestra legislación laboral con un claro sentido pro operario. Más que proponer una mera derogación de los cambios introducidos durante el proceso de reformas 2010-2013, lo que se hace es presentar una serie de medidas que, a juicio de los firmantes, deben adoptarse con carácter urgente para cambiar la tendencia de la legislación laboral en los últimos años, más que centrarse en una ley determinada. En sus palabras,

"es necesario derogar el contenido esencial de las últimas reformas laborales. Es necesario impulsar un cambio de tendencia que permita recuperar los derechos laborales y sociales, por los que lucharon con gran sacrificio anteriores generaciones, y conquistar nuevos derechos en la perspectiva de construir una sociedad más justa y libre de toda forma de explotación".

Para ello, proponen "quince medidas que permitirían iniciar ese cambio de tendencia y hablar con propiedad de una derogación de las reformas laborales"; esto se hace "como primera iniciativa". Pues bien, entre estas, aparece una dirigida directamente a la regulación de las consecuencias laborales de la subcontratación, con el siguiente contenido: "Prohibición de externalización de servicios prestados anteriormente con personal de la propia empresa; prohibición de subcontratación de servicios que formen parte esencial del mismo proceso productivo o servicio prestado".

Se trata, en realidad, de dos medidas diferentes. La primera supone prohibir la externalización de servicios prestados anteriormente con personal de la propia empresa; una medida cuyos efectos son difíciles de delimitar, toda vez que la referencia a "servicios prestados anteriormente" puede ser amplísima. Llegando al absurdo, 
pareciera que hay que revisar todas las decisiones de externalización adoptadas por las empresas a lo largo de la historia, muchas de las cuales deberían anularse por contrariar esta prohibición. Tampoco se aclara cuáles serán las consecuencias prácticas de esta prohibición sobre los contratos de servicios entre las empresas y de trabajo entre las contratistas y sus trabajadores.

La segunda medida está en la línea de lo propiciado por los documentos elaborados por el Gobierno para la reforma laboral, y supone eliminar la subcontratación de servicios que formen parte esencial del mismo proceso productivo o servicio prestado. Es una medida de mucho más calado, ya que afectaría a todas las empresas, que tendrían que revisar su política de externalización; y que obligaría a muchas de éstas a internalizar parcelas de su actividad, rompiendo con proveedores de servicios y, según los casos, pudiendo verse obligadas a asumir las plantillas de estos adscritas a la contrata. La propuesta no contempla medidas de carácter transitorio o facilitadoras de la aplicación de esta nueva regla. Las dudas sobre su practicabilidad y sobre su legitimidad, desde el punto de vista de la libertad de empresa, son numerosas.

Circulan, como se ve, numerosas iniciativas desde ámbitos diversos, pero que se ubican en una única línea de tendencia al apuntar en una misma dirección. Todas dibujan, de alguna manera, un nuevo modelo de ordenación de la subcontratación. Este vendría caracterizado por una serie de claves, al igual que el vigente; solo que algunas de estas suponen cambios trascendentales respecto de lo que ahora tenemos. Para poder valorar adecuadamente el alcance de estos cambios, utilizaremos el mismo esquema desarrollado para presentar el modelo vigente, identificando las novedades respecto de este:

- La libertad de subcontratar tiende a limitarse, al prohibirse ciertos tipos de externalización, como los relativos a la propia actividad de la empresa, o los desarrollados directamente por la empresa principal. Los documentos elaborados por el Gobierno abandonan esta idea, pero no debemos destacarla para el futuro.

- La libertad para prestar servicios como empresa contratista no parece haberse visto reducida, aunque se le imponen nuevas obligaciones y limitaciones en su forma de contratar y suministrar mano de obra.

- Se mantienen los principales sistemas de garantía utilizados tradicionalmente, aunque se potencian: se pretende extender, así, el alcance de la responsabilidad solidaria para afectar a cualquier tipo de subcontratación; y se potencian los derechos de información de los representantes de los trabajadores.

- Se mantiene la regla de que el empleador es la empresa contratista, sin que la empresa principal adquiera esta condición. Ahora bien, las consecuencias de este hecho se reducen considerablemente, al fortalecerse la vinculación con la empresa principal. La responsabilidad de esta respecto 
de las obligaciones laborales de los empleados de la contratista, terceros en principio, se fortalece. La idea de usar como referencia para la determinación de las condiciones de trabajo no la situación en la contratista empleadora, sino en la principal beneficiaria de los servicios, mediante un mecanismo de equiparación salarial, parece haberse abandonado por el momento.

- Desde el punto de vista de la contratación laboral se producen importantes novedades. La contrata ya ha dejado de ser considerada una obra o servicio a efectos de legitimar la celebración de contratos temporales, por obra del Tribunal Supremo. Todas las propuestas mantienen esta solución, lo que obligará a cambiar radicalmente la política de recursos humanos en las empresas especializadas en prestar servicios a otras empresas por esta vía.

- En los documentos manejados no se aclara si la finalización de la contrata seguirá siendo causa legítima de extinción de los contratos de trabajo. Hubo propuestas en la primera década del siglo que pretendían mejorar la calidad del empleo en los supuestos de externalización, introduciendo una obligación de contratación indefinida para las contratistas, que se acompañaba de la previsión, como una nueva causa de despido, de la propia finalización de la contrata. En su momento, se presentó como una solución basada en los esquemas de la flexiguridad -a mi juicio, muy acertada-, que desgraciadamente no llegó a ponerse en práctica.

- En el nuevo modelo resulta claro también que el cambio de contratista tiende a ser considerado una posible sucesión de empresas. Los textos manejados no se ocupan de esta cuestión, pero la tendencia de los tribunales laborales españoles a ampliar la aplicación del artículo 44 del Estatuto de los Trabajadores a este tipo de situaciones es evidente, motivada en parte por las indicaciones del Tribunal de Justicia de la Unión Europea.

Estas son, a mi juicio, las claves del nuevo modelo de ordenación del trabajo en contratas en el Derecho del Trabajo español. Unas se han introducido ya; algunas están, a lo que parece, a punto de hacerlo; y otras se han discutido, pero se han dejado de lado. Sea como fuere, lo cierto es que la nueva regulación supone cambios de gran alcance respecto al modelo tradicionalmente seguido en España, por lo que la denominación de este modesto análisis - “cambio de paradigma”-, entiendo pueda estar justificada. 